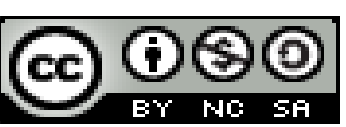

Ciencias de la educación

Artículo de investigación

\title{
Matrices disciplinares y fuentes teóricas de los Cultural Studies, perspectiva inter y transdisciplinar en el análisis de los procesos culturales y nuevo discurso
}

\author{
Disciplinary matrices and theoretical sources of Cultural Studies, inter and \\ transdisciplinary perspective in the analysis of cultural processes and new discourse
}

\section{Matrizes disciplinares e fontes teóricas de Estudos Culturais, perspectiva inter e transdisciplinar na análise de processos culturais e novos discursos}

\author{
Rosa L. Cedeño-Rengifo I \\ jirosac21@hotmail.com \\ Gabriela L. Vélez-Bermello II \\ gabriela.velez@uleam.edu.ec \\ Jessica F. Ostaiza-Macías III \\ jessicaostaiza172@hotmail.com
}

Recibido: 05 de septiembre de 2017 * Corregido: 28 de octubre de 2017 * Aceptado: 05 de diciembre de 2017

1. Magister en Gerencia Educativa, Profesora de Segunda Enseñanza Especialidad Educación Primaria, Licenciada en Ciencias de la Educación Especialidad Educación Primaria, Docente Universidad Laica Eloy Alfaro de Manabí, Manta, Ecuador.

II. Magister en Periodismo, Licenciada en Ciencias de la Comunicación Mención Periodismo, Docente Universidad Laica Eloy Alfaro de Manabí, Manta, Ecuador.

III. Magister en Administración de Empresas Mención en Negocios Internacionales, Ingeniera Comercial, Docente Universidad Laica Eloy Alfaro de Manabí, Manta, Ecuador. 


\title{
Resumen
}

Los Cultural Studies son un campo de investigación de carácter interdisciplinario y transdisciplinario, que explora las formas de producción o creación de significados y de difusión de los mismos en las sociedades actuales. Desde esta perspectiva, la creación de significado y de los discursos reguladores de las prácticas significantes de la sociedad revela el papel representado por el poder en la regulación de las actividades cotidianas de las formaciones sociales. En este trabajo se argumenta la variedad de matrices disciplinares y fuentes teóricas de los Estudios Culturales: semiótica, antropología, marxismo, entre otras. Además, se explican los desplazamientos promovidos en este campo de estudios por la apertura de nuevas áreas de indagación como el género y la raza, es decir el nuevo discurso que aparece. Todo ello responde al análisis de fuentes de información.

Palabras clave: teoría de la comunicación; estudios culturales; transdisciplinariedad; interdisciplinariedad; discursos.

\begin{abstract}
Cultural Studies is an interdisciplinary and transdisciplinary research field that explores the forms of production or creation of meanings and their diffusion in current societies. From this perspective, the creation of meaning and the regulatory discourses of the significant practices of society reveals the role represented by power in the regulation of the daily activities of social formations. In this paper, the variety of disciplinary matrices and theoretical sources of Cultural Studies is argued: semiotics, anthropology, Marxism, among others. In addition, the displacements promoted in this field of studies are explained by the opening of new areas of inquiry such as gender and race, that is, the new discourse that appears. All this responds to the analysis of information sources.
\end{abstract}

Keywords: communication theory; cultural studies; transdisciplinarity; interdisciplinarity; speeches

\section{Resumo}

Estudos culturais é um campo de pesquisa interdisciplinar e transdisciplinar que explora as formas de produção ou criação de significados e sua difusão nas sociedades atuais. Nesta perspectiva, a criação do significado e os discursos regulatórios das práticas significativas da sociedade revelam o papel representado pelo poder na regulação das atividades diárias das formações sociais. Neste artigo, discute-se a variedade de matrizes disciplinares e fontes teóricas de Estudos Culturais: semiótica, antropologia, marxismo, entre outros. Além disso, os deslocamentos promovidos neste campo de 
estudos são explicados pela abertura de novas áreas de pesquisa, como gênero e raça, ou seja, o novo discurso que aparece. Tudo isso responde à análise de fontes de informação.

Palavras chave: teoria da comunicação; estudos culturais; transdisciplinaridade; interdisciplinaridade; discursos.

\section{Introducción}

Solo una palabra, o mejor dicho, solo los significados de cultura, "una de las dos o tres palabras más complicadas de la lengua inglesa" (Williamas, 2003, p. 87), fueron necesarios para obtener la paella teórica de los estudios culturales.

Quizás esa no es la metáfora más apropiada porque la paella, es un símbolo culinario de España, y los Cultural Studies tienen mayor relación con Gran Bretaña y los Estados Unidos; pero sí es la precisa para ilustrar "los discursos múltiples, las historias numerosas y diferentes, un conjunto amplio de opciones, varios tipos de actividades, personas que tenían y tienen diversas trayectorias, un gran número de metodologías y de posiciones teóricas diferentes" (Hall citado por Grandi, 1995, p. 2), qué constituyeron los Cultural Studies.

El inicio de este campo de investigación se enmarca en la posguerra británica, cuando Inglaterra se vio inmersa en una caída cultural tangible. Sin embargo, ya desde la mitad del siglo XIX, el país sufría las problemáticas de una sociedad ahogada por los medios de comunicación y por las ideologías que el Estado establecía arbitrariamente.

Con la Primera Guerra Mundial, Gran Bretaña, y en especial los intelectuales, comenzaron a movilizarse con el propósito de una recuperación cultural. Así, surgen entre los conservadores investigaciones y teorías sobre la temática.

"Los Estudios Culturales se fundaron en un cambio del análisis dominante o prácticas culturales de élite hacia el análisis de las prácticas culturales populares. Pretendían dar a la clase trabajadora un sentido del valor de sus propias prácticas y experiencias cotidianas, opiniones y manifestaciones características en contra de la cultura dominante" (Rosas, 2012, p. 5).

El panorama social, cultural y político en Inglaterra después de la Segunda Guerra Mundial, como puntualiza Graeme Turner, se caracterizó por: 
1. "La recuperación de la producción industrial, la afirmación del Welfare State, la unidad de Occidente contra la Unión Soviética, la predicción de la desaparición de la clase obrera y la identificación de la modernidad con la americanización de la cultura popular;

2. la recuperación, dentro de las ciencias sociales, de un interés por la naturaleza de la cultura y por las comunidades obreras;

3. la actividad del Institute of Contemporary Arts (ICA) de Londres, que abarcaba muchos aspectos de la cultura popular, incluidos los visuales, sobre todo los relativos a la influencia de la cultura popular estadounidense en la vida británica;

4. la actividad de la enseñanza para adultos que en los años treinta y cuarenta había implicado tanto a Richard Hoggart como a Raymond Williams. Este último recordó reiteradamente el significado de la actividad de esas organizaciones obreras de autoeducación en el desarrollo de los Estudios culturales, ya que a finales de los años cuarenta la gente hacía cursos de artes visuales, música, planificación territorial y naturaleza de la comunidad, naturaleza de los asentamientos, cine, prensa, publicidad, radio (1989b). Según Martin Barker y Anne Beezer (1992), el resumen de Williams y de muchos otros biógrafos de los Estudios culturales sobre la educación para adultos de la posguerra peca, por un lado, de reduccionismo y, por el otro, de romanticismo" (Citado por Grandi, 1995, p. 7-8).

A esas cuatro características sería preciso agregar otra que surge con la imposición del régimen nazi y la posterior huida de prestigiosos intelectuales como Norbert Elias, Arnold Hauser, Karl Manheim y Karl Polanyi. Según Mattelart y Neveu, la llegada de dichas figuras emigradas "contribuirá a sentar una visión positiva de las ciencias sociales e influirá profundamente en la formación de una sociología de la cultura y de una ciencia de la sociedad" (2004, p. 38).

Asimismo, en el contexto de emergencia de los Estudios Culturales incidió una corriente de investigación denominada Cultura y civilización, enarbolada por figuras intelectuales del humanismo romántico que veían a la cultura conceptualizada por procesos de industrialización y de urbanización. Ellos entendían la civilización como un proceso de masificación y atomización de los individuos, y a la cultura, como un organismo viviente (Grandi, 1995, p. 8) Defendían el criterio de que los críticos debían asumir "el papel de defensor de la cultura común, explicando al pueblo los mecanismos de 
funcionamiento del proceso de industrialización. Por tanto, esta cultura común solo se puede alcanzar en virtud de la intervención guía de una elite que realice una crítica literaria destinada a acercar las obras al público" (Grandi, 1995. p. 8).

Los planteamientos de la Cultura y civilización eran, como expresa Tony Bennett, "discursos de los cultos sobre la cultura de quien no poseía cultura" (Citado por Grandi, 1995, p.8).

Este trabajo tiene el propósito de abordar las matrices disciplinares y las fuentes teóricas de las cuales parten los Cultural Studies ingleses, así como su apuesta por una perspectiva inter y transdisciplinar en el análisis de los procesos culturales. Además, explicar los desplazamientos promovidos en este campo de estudios por la apertura de nuevas áreas de indagación como el género y la raza.

\section{Metodología}

Este trabajo se basa en el análisis documental, para ellos se localizan y revisan diferentes fuentes de información. Se seleccionan las que responden al tema de estudio y se sintetizan, organizan y engranan los contenidos.

\section{Desarrollo}

\section{Fuentes y matrices: inter y transdisciplinariedad}

Los estudios culturales beben de teorías, estudios e investigaciones centradas en la cultura popular y la comunicación social. Estos estudios no reproducen los criterios de sus fuentes, sino las critican y, a partir de ellas, construyen su propia postura. Una de estas fuentes es el marxismo.

Los padres fundadores de los Cultural Studies, quienes representaron un papel primordial en la etapa de maduración que culminó con el reconocimiento institucional de los Estudios Culturales en 1960, se relacionaron de diversa forma con la ideas marxistas.

El interés por el socialismo de Richard Hoggart, uno de los padres fundadores, "no venía marcado por una agenda ideológica específica, sino por la simpatía vital que, como hijo de una familia de clase trabajadora en la ciudad de Leeds, tuvo siempre por la situación de los obreros" (Castro, s/f, p.2).

En la obra de Hoggart, The Uses of Literacy: Aspects of Working- Class Life with Special References to Publications and Entertainments, traducido al francés como La Culture du pauvre, libro que es 
considerado la base del campo de estudios de los Cultural Studies, Hoggart describe y critica la nefasta situación de los obreros británicos, observada por el autor durante su infancia: "Este libro se basa en buena parte en experiencias personales y no pretende poseer el carácter científicamente experimentado de la investigación sociológica" (Hoggart citado por Grandi, 1995, p.9).

Hoggart denuncia la influencia que los nuevos medios de comunicación ejercían sobre los obreros: Sobre el tema, expresa Turner: "El cine, la televisión y las revistas de entretenimiento han desarraigado a los obreros de su propia cultura, exponiéndolos a la perversa influencia de la sociedad de consumo" (Citado por Castro, s/f, p.3).

Por otra parte, Raymond Williams (1921-1988) fue integrante del Partido Comunista durante su juventud y recibió una mayor influencia del marxismo. Willams adoptó una posición crítica ante esta doctrina política y filosófica, alejada del irracionalismo economicista: "la economía ya no se consideraba tanto un sistema de producción cuanto un sistema de conservación, que jugaba un papel dentro de la red de control propia del capitalismo occidental, junto con otros componentes" (Grandi, 1995, p. 11).

"Williams opina que el marxismo trabaja con un concepto doblemente reducido de cultura: de un lado, la convierte en un reflejo distorsionado de la infraestructura económica; del otro, la limita a las manifestaciones de la cultura letrada; arte, filosofía, literatura.

La cultura por la que Williams se interesa no es la de los productos simbólicos de las elites, sino la de la "experiencia vivida" por las clases trabajadoras inglesas en el seno de las grandes ciudades industriales. Williams entiende la cultura como expresión "orgánica" de formas de vida y valores compartidos que no pueden ser reducidas a ser epifenómeno de las relaciones económicas. Los estudios culturales deben concentrarse en el análisis de las culturas populares urbanas, descubriendo cuál es la "sensibilidad particular" que atraviesa todas sus estructuras sociales" (Castro, s/f, p.3).

Sobre los planteamientos de William acerca de la cultura, Jenks expresa: "Williams es un marxista que considera la cultura de la clase obrera como una aportación a una cultura común. No queda ninguna huella de los antagonismos de clase, anulados por un sentido comunitario que se superpone a la noción de contradicción" (Citado por Grandi, 1995, p. 12). 
Williams estuvo vinculado con la New Left, evidencia de ello es la declaración de uno de los principales referentes de los Estudios Culturales, Stuart Hall, en Vida y momentos de la primera nueva izquierda: "Nadie expresó tan profundamente como Raymond Williams el carácter fundamental y constitutivo de este argumento para la Nueva Izquierda y dentro de ella" (s/f, p. 173) Se refería a la crítica de la civilización y la cultura capitalista.

De igual forma, Edward Thompson se vio relacionado con el marxismo y con el New Left. Fue miembro del Partido Comunista y era partidario de un socialismo humanista que pudiera garantizar a las clases populares la capacidad de independizarse y adueñarse de sus vidas.

"Con Williams comparte sobre todo el mismo deseo de superar los análisis que han convertido a la cultura en una variable sometida a la economía y que, además de legitimar el estalinismo, han aplazado sine die la reflexión sobre las formas culturas. El trabajo de Thompson puede escribirse como el prejuicio de una historia centrada en la vida y en las prácticas de resistencia de las clases populares" (Mattelart \& Neveu, 2004, p.40).

Una de las grandes obras de Thompson es The Making of the English Work Class (1963), "clásico de la historia social y reflexión sobre la socio historia de un grupo social" (Mattelart \& Neveu, 2004, p.41).

Evidencia de la profunda relación de los Estudios Culturales con el marxismo, es lo que expresa Stuart Hall: "Habíamos surgido y vivíamos en la época de los muchos marxismos. Para algunos de nosotros tuvo una gran importancia el redescubrimiento de los primeros Manuscritos económicos y filosóficos de Marx, con sus temas de la alienación, el ser de la especie y las nuevas necesidades" ((s/f), p.173).

Con el cambio de paradigmas del campo de investigación: del paradigma humanista, inspirado en los estudios literarios, al paradigma estructuralista, inspirado en el psicoanálisis y la teoría social marxista; y a partir de la obra de Louis Althusser y Antonio Gramsci; los Cultural Studies "pretendieron refutar la tesis de otras interpretaciones marxistas de la comunicación de masas, especialmente de la economía política" (Quirós citado por Rosa, 2012, p.8).

Althusser, "aun reconociendo la importancia de la vida cotidiana, no puede escapar de las tesis marxistas que demonizan al estado y, recluido en esa cárcel conceptual, propone una estatización de 
una serie de instituciones sociales conceptualizadas como Aparatos ideológicos del Estado. Esta, sin embargo, abre un nuevo espacio de acción política: las prácticas cotidianas de la sociedad civil" (Repoll, 2010, citado por Rosas, 2012, p.8).

Una de las matrices disciplinares de los Cultural Studies ingleses es la Semiótica. Williams consideraba este campo disciplinar "como un método de análisis textual” (Grandi, 1995, p.12).

Stuart Hall se fundamenta en la semiótica para analizar el proceso comunicativo en su libro codificación y descodificación en el discurso televisivo.

"Los estudios culturales parten de la idea de que el texto (sea éste una novela, una revista, una película, un videojuego, etc.) es una serie estable de sentidos, de modo que el análisis textual es fundamental, siempre bien entendido que la lectura de todo texto es necesariamente intertextual" (Jordan citado por Clúa, 2008, p.16).

También, los Cultural Studies tienen sus raíces en la antropología. Según expone Jenks: "Se adhieren al punto de vista antropológico de la cultura entendida como el modo de vida completo de un pueblo, a pesar de que no concuerden con el punto de vista que define la cultura en cuanto totalidad" (1993, citado por: Grandi, 1995).

Al respecto, Rosas puntualiza: "La disciplina con la que, quizá, exista un mayor grado de similitud es con la antropología cultural, la cual estudia la sociedad y la cultura humanas, describiendo y explicando, analizando e interpretando las similitudes y diferencias culturales. Para estudiar e interpretar la diversidad cultural los antropólogos culturales realizan dos tipos de actividad: la etnografía (basada en el trabajo de campo) y la etnología (basada en la comparación transcultural) Mientras que los estudios culturales tratan y describen los comportamientos culturales de un grupo en particular, contextualizando" (2012).

Sobre la variedad de matrices disciplinares y fuentes teóricas de los Estudios Culturales: semiótica, antropología, marxismo; así como estructuralismo, posestructuralismo, humanidades, sociología y teorías feministas, argumenta Grandi: "Lo que acomuna esta pluralidad de opciones teóricometodológicas observada reiteradamente, que a veces entran en recíproca contradicción, es el hecho de preferir, en cuanto marco de sentido más amplio, la actividad de investigación, entendida como 
actividad crítica: el desarrollo teórico ha de ir acompañado de un compromiso a nivel de proyecto político" (1995, p.3).

Sin dudas, una de las características más sobresalientes de los Cultural Studies es su apuesta por una perspectiva interdisciplinar, transdisciplinar y contradisciplinar. Grossberg, Nelson y Treichler definen este campo de investigación: "Los Estudios Culturales son un campo interdisciplinar, transdisciplinar y a veces contradisciplinar, que actúa en medio de la tensión de sus mismas tendencias para acoger un concepto de cultura que sea amplio y antropológico y, a la vez, restringido y humanista" (1992, p.5).

\section{Nuevo discurso}

En 1970, los Cultural Studies se trasladan a los Estados Unidos. "En esa época ocurrían una serie de acontecimientos que no podían ser menospreciados por el desarrollo universitario de corrientes críticas, tales como conexiones con las turbulencias europeas de los años sesenta, los movimientos por los derechos civiles de los negros, el feminismo y las contraculturas" (Rosas, 2012, p.10).

Sin embargo, en la década de los 80 , se propaga una política de derecha y, además habían conflictos dentro del movimiento feminista.

Es a finales de la década del 70 y durante los años 80 que los Cultural Studies experimentan un giro etnográfico: "El cuestionamiento de la cultura en la vida cotidiana se extenderá concéntricamente como una mancha de aceite, la cual tendrá finalmente dos ampliaciones" (Mattelart \& Neveu, 2004, p.56) Esas dos ampliaciones fueron, por un lado, las cuestiones de género, y por otro, las comunidades inmigrantes y el racismo.

Dentro de la cultura popular, los Estudios Culturales adoptan la temática del feminismo, que según Grandi "penetró como una potente llave maestra capaz de hacer saltar todos los equilibrios precedentes: se colocan en el centro de interés ternas que se consideraban marginales, se ponen en cuestión metodologías bien rodadas, se someten a una fuerte réplica tanto la misma modalidad de considerar la relación entre teoría y práctica critica como la gestión del Centro” (1995, p.15).

Una de las raíces feministas es el libro de Betty Friedan, The Feminine Mystique. En su segundo capítulo, The Happy Housewife Heroine, Friedan "aborda el análisis de las revistas femeninas, 
fundamentalmente para denunciar la imagen de la feminidad de la que son transmisoras, al mismo tiempo que acusa también a la publicidad, las películas, la televisión, las novelas, etc. como proveedoras de imágenes que forman la vida de las mujeres y se constituyen como espejos de éstas" (Clúa, 2008, p.20).

Desde los primeros debates culturales abordados con un punto de vista feminista, se percibe una gran desconfianza en el aspecto de la cultura popular. (Clúa, 2008, p.20) Según expresa Hollows, "acusar a la cultura popular de reforzar o proporcionar imágenes conservadoras de la mujer implica un triple error teórico:

1) se asume que la cultura popular representa identidades de género $y$, como se ha mostrado posteriormente, el proceso no es tan simple y mecánico; más bien lo que hace es construir y estructurar el significado del género;

2) se asume que lo que muestra, dice o propone la cultura popular tiene una única interpretación, es decir, que los textos son autoevidentes, pero, como se ha mostrado, los textos son polisémicos y su decodificación depende de los distintos repertorios que utiliza el lector/la lectora, $\mathrm{y}$

3) se asume que todos los intérpretes lo decodifican de un mismo modo lo que, en último término, implica concebir un/a intérprete monolítica y uniforme y, como se ha mostrado posteriormente desde la misma crítica feminista, la categoría mujer difícilmente puede reducirse a una etiqueta uniforme, pues encubre una diversidad de experiencias y definiciones" (Citado por Clúa, 2008, p.20)

Durante los años 70, con la segunda ola de investigaciones, tiene gran relevancia la figura de Ángela McRobbie. En su libro Feminism and Youth Culture (1991), la autora aborda específicamente el sector de los jóvenes, al igual que Friedan. "Su perspectiva en este y otros trabajos es diametralmente distinta a la de Friedan, enfatiza cómo ciertos mensajes pueden ser positivos y proporcionar un marco de empoderamiento. De hecho, en el trabajo de McRobbie puede ya trazarse la incipiente irrupción del feminismo de la tercera ola, pues ya se constatan en él las divergencias entre las generaciones de jóvenes de mujeres y el pensamiento feminista clásico" (Clúa, 2008, p.21).

Mc Robbie en su ensayo The Politics of Feminist Research, sostiene que "las primeras obras feministas, bajo la influencia conjunta del legado de la izquierda en el movimiento de mujeres y de 
las conexiones marxistas de la ciencia social, se sintieron empujadas a incluir la clase en todos sus estudios" (Barker, 1994, p.23-24).

Y, asimismo, adoptó el criterio de que "las explicaciones sólo pueden tener fuerza si se las encuentra en el interior del discurso de las personas que estamos estudiando" (Barker, 1994, p.24).

Las feministas se pronunciaron contra los soap opera, programa televisivo dedicado a las mujeres que se caracteriza por las diversas tramas y el sentimiento excesivo. Como expresa Barker: "Las feministas querían distanciarse de textos femeninos antiermancipatorios (1994, p.24).

Según Rakow," las aproximaciones feministas al análisis de la cultura popular pueden resumirse en cuatro grandes modos: 1) el análisis de las imágenes de la mujer producidas por la cultura popular; 2) la recuperación y relectura de la cultura popular creada por mujeres; 3) el estudio de la recepción y consumo de la cultura popular por parte de las mujeres, y 4) la formulación de una teoría cultural feminista" (Citado por Clúa, 2008, p.21).

El feminismo se sitúa en dos posiciones simultáneas, según puntualiza Hollows, "en parte se coloca fuera y contra la cultura popular, mientras que otra parte asume su estudio como un área prioritaria de trabajo, entre otras razones porque se entiende que la formación de las subjetividades contemporáneas, incluyendo las marcas de género, pasa necesariamente por el universo de lo popular" (citado por Clúa, 2008, p.23).

Por otro lado, los Estudios Culturales "no solo consideraron el tema del racismo desde un punto de vista general, sino también las intervenciones de la actividad crítica sobre la politización de la cuestión racial y los intentos de volver a escribir la historia (por ejemplo, The Empire Strikes Back), a través del desplazamiento radical del punto de vista que teorizaba y practicaba en las investigaciones poscoloniales" (Grandi, 1995, p.15).

Mattelart y Neveu exponen: "La multiplicación de las tensiones raciales, el auge de los grupos racistas, así como las movilizaciones originadas por dichos fenómenos (ver el compromiso de los "Clash" en Rockagainst Racism), están presentes en la producción del Centro" (2004).

"La fractura de los paisajes sociales (social Iandsmpes) en las sociedades industriales avanzadas, con la consecuencia de que el yo (self) forma parte, de ahora en adelante, de un proceso de elaboración de 
identidades sociales, en el que el individuo se define con respecto a distintas coordenadas, sin que pueda quedar reducido a una o varias de dichas coordenadas (ya se trate de la clase, la nación, la raza, la etnia o el género), argumentó Hall, en 1991, como uno de los factores que obligaban al nuevo posicionamiento de los Cultural Studies. (Citado por Mattelart \& Neveu, 2002).

Este campo de estudios desplaza determinados planteamientos de algunas teorías precedentes. En el texto de Hall, Codificación y descodificación en el discurso televisivo, el autor plantea que los programas televisivos son textos abiertos y generadores de diversas interpretaciones: "Antes de que este mensaje pueda producir un efecto (sea como fuera que se defina), o satisfacer una necesidad o engendrar un uso, debe ser primero percibido como un discurso con sentido y descodificado con un significado" (2004).

Estos postulados divergen de la corriente empírico experimental, la cual planteaba que "La persuasión de los destinatarios es un objetivo posible siempre que la forma y la organización del mensaje sean adecuados a los factores personales que el destinatario activa en la interpretación del mismo mensaje" (Wolf, (s/f), p.17).

Hall también expresa la relación existente entre el contexto de la audiencia y sus significados, y la presencia entre el texto y el espectador de un proceso negociador, donde el receptor no es un sujeto pasivo de significados ya construidos (2004).

Y, además, plantea la asimetría del proceso comunicativo: "Los códigos de codificación y descodificación pueden no ser totalmente simétricos. Los grados de simetría, esto es, los grados de entendimiento y malentendido en el intercambio comunicativo dependen ambos del grado de simetría y asimetría entre la posición del codificador-productor y la del descodificador-receptor; y también, de los grados de identidad falta de identidad entre los códigos que se transmiten perfecta o imperfectamente, que dificultan o distorsionan sistemáticamente, aquello que ha sido enviado" (Hall, 2004, p.20).

Entender la comunicación como un proceso asimétrico remite al criterio de la Teoría hipodérmica. Según esta última: "Cada individuo es un átomo aislado que reacciona por separado a las órdenes y las sugerencias de los medios de comunicación de masas monopolizados" (Wright citado por Wolf, (s/f), p.11). 
Wolf, en relación a las diferencias entre los Cultural Studies y la teoría que él denomina teoría conspiradora de los medios, explica: "La teoría conspiradora de los medios establece una relación entre los contenidos de los media y el objetivo de control social perseguido por las clases dominantes. La censura de algunos temas, el énfasis puesto en otros, la presencia de mensajes evasivos, la deslegitimación de los puntos de vista marginales o alternativos son algunos de los elementos que hacen de los mass media un puro y simple instrumento de hegemonía y de conspiración de la élite del poder.

Frente a esta versión los Cultural Studies, al reafirmar la centralidad de los productos culturales colectivos como agentes de la continuidad social, enfatizan la naturaleza compleja y elástica, dinámica y activa, no puramente residual o mecánica. Al subrayar una vez más el hecho de que las estructuras sociales en torno al sistema de los media y las específicas condiciones históricas son elementos esenciales para comprender las prácticas mediológicas, los cultural studies ponen de manifiesto la continua dialéctica entre sistema cultural, conflicto y control social” (s/f, p.63)

\section{Conclusiones}

Los Estudios Culturales, a diferencia de otras teorías, comprende la recepción vinculado con la cotidianidad: "Estudiosos como David Morley, Dorothy Hobson, Angela Mc Robbie, y Robert Hodge y David Tripp se han detenido a trabajar cómo los actuales grupos de audiencias usan activamente la televisión como una parte de sus propias culturas, esto es, la usan para construir sentidos que les son útiles en la significación de su propia experiencia y de sí mismos" (Fiske, 1987, p.5).

A diferencia de la Escuela de Frankfurt que no confía en la capacidad de las masas de generar su propia cultura, los Estudios Culturales sostienen que "la gente aún maneja la construcción de sus propios sentidos y la construcción de su propia cultura dentro de, y frecuentemente en contra de, aquella que la industria le proporciona" (Fiske, 1987, p.12).

De igual forma, los Cultural Studies se preocupan por el contexto y defienden una perspectiva cualitativa para comprender al receptor. "El aspecto central que se debe tener en cuenta es la lógica que rige la conducta cotidiana situada, a fin de llegar a entender cómo se desarrollan los proceso de comunicación en sus escenarios naturales y cómo, en este contexto, se incorporan y movilizan en el interior de esos mundos privados los diferentes medios públicos” (Morley, 1996, p.267). 


\section{Referencias Bibliográficas}

Barker, M. (1994). Introducción a los estudios culturales. España: Bosch Casa Editorial

Castro, S. (s/f). Althusser, los estudios culturales y el concepto de ideología. Bogotá: Estudios sociales y culturales pensar

Clúa, I. ¿Tiene género la cultura? Los estudios culturales y la teoría feminista. En Clúa, I. (2008) Género y cultura popular. Barcelona: Edicions UAB

Fiske, J. Los estudios culturales británicos y la televisión. En: Allen, Robert. (1987).Channels of discourse. Television and contemporary criticism. North Carolina: University of North Carolina Press

Grandi, R. (1995). Texto y contexto en los medios de comunicación. Barcelona: Bosch Casa Editorial

Hall, S. (s/f). Vida y momentos de la primera nueva izquierda

Hall, S. (2004). Codificación y descodificación en el discurso televisivo. Cuadernos de Información y Comunicación (9)

Mattelart, A. y Neveu, E. (2002). Los Cultural Studies. Hacia una domesticación del pensamiento salvaje. Argentina: Ediciones de Periodismo y Comunicación No. 20

Mattelart, A. y Neveu, E. (2004). Introducción a los Estudios Culturales. Barcelona: Paidós

Rosas, K. (2012). Genealogía de los Estudios Culturales. Recuperado en abril de 2015, de la revista electrónica Razón y Palabra: http://www.razon ypalabra.org.mx

Williamas, R. (2003). Palabras claves. Un vocabulario de la cultura y la sociedad. Buenos Aires: Ediciones Nueva Visión

Wolf, M. (s/f). La investigación de la comunicación de masas. La Habana: Pablo de la Torriente 
Matrices disciplinares y fuentes teóricas de los Cultural Studies, perspectiva inter y transdisciplinar en el análisis de 